\title{
Photogrammetric evaluation options of an ancient monument for different survey levels
}

\author{
Funda Uygun ${ }^{\mathrm{a}, *}$, Mine Hamamcioğlu Turan ${ }^{\mathrm{a}}$, Ogan Ocalı ${ }^{\mathrm{b}}$ \\ a İzmir Institute of Technology, Faculty of Architecture, Architectural Restoration Department, IYTE, Gülbahçe, Urla, İzmir 35430, Turkey \\ b Izmir Institute of Technology, District of Technology Development, IYTE, Gülbahçe, Urla, İzmir 35430, Turkey
}

\section{A R T I C L E I N F O}

Article history:

Received 17 March 2016

Received in revised form 24 May 2016

Accepted 10 June 2016

\section{Keywords:}

Image based modeling

Ancient monument

Documentation

Condition report

Structural survey

\begin{abstract}
A B S T R A C T
Recently, for the purpose of data management, more advanced digital data are required for different survey levels of irregular ancient monuments. For irregularly formed monuments and amorphous surfaces, 2D photographs and 2D measured surveys are inadequate to illustrate the condition of the building for condition reports or relationships between components and materials for structural surveys and conservation decisions, especially in archeological remains. However, image-based documentation techniques can be used as simple tools for different types of surveys due to their ease of use and fast and economical properties. Therefore, the aim of the study is to test multi-image photogrammetric documentation techniques to improve and standardize visual data appending condition reports and further detailed reports regarding conservation of irregular ancient monuments.

In the literature, there are many studies about image-based documentation techniques. However, the innovation of the study is to provide an improvement of the pipeline of condition and structural surveys of irregular ancient monuments by making use of photogrammetric techniques.

In order to measure the effects of the relationship between the type of documentation technique and survey level on the photogrammetric documentation process of an ancient monument, a series of experiments were designed and the results compared. For this purpose, automated image orientation packages Autodesk 123D and Photosynth and manual image orientation package Tgi3D were evaluated in terms of process time, reliability and level of detail to identify appropriate techniques for different survey levels.

This study proved that documentation of the structural characteristics of ancient monuments can be achieved successfully with the Tgi3D package, which has manual workflows. The documentation results might support structural intervention decisions. The 3D models based on automatic workflows might support a preliminary condition survey, since their production takes a relatively short time and scaled models are acceptable for identifying mass characteristics.
\end{abstract}

(c) 2016 Elsevier Ltd. All rights reserved.

\section{Introduction}

According to the standards of the European Committee for Standardization, the first step in the conservation of cultural property is the preparation of a condition survey. Then, the data gathered from the condition survey are used for the identification of the next steps such as preventive conservation, maintenance, immediate repairs, and planning for further studies when causes of damage are not evident (UNI EN 16096, 2012).

The condition report includes assessment, documentation and recording of the condition of cultural heritage buildings to keep them in a well-maintained condition. For the purpose of data management, it

\footnotetext{
* Corresponding author.

E-mail addresses: fundauygun@iyte.edu.tr (F. Uygun), mineturan@iyte.edu.tr (M. Hamamcıoğlu Turan), oganocali@gmail.com (O. Ocalı).
}

is advisable to establish a digital system in the condition survey and the related visual sources such as old and current photographs, old drawings, earlier inventories, earlier conservation plans, etc. Although information on the height and ground area of the building is necessary for the condition survey, the present reporting form does not include a measured survey of the current state, which is a time-consuming process. This study suggests that automatic image-based modeling techniques are user friendly and fast tools for measured surveys of the mass of irregular formed ancient monuments in $1 / 200$ and $1 / 500$ scale. However, if further studies such as a structural diagnosis are necessary, then manual image based modeling techniques are economical tools for detailed and reliable measured data.

The innovation of the study is to provide an improvement of the pipeline of the condition and structural survey of ancient monuments by making use of image based photogrammetric techniques. The aim of the study is to test multi-image photogrammetric documentation 


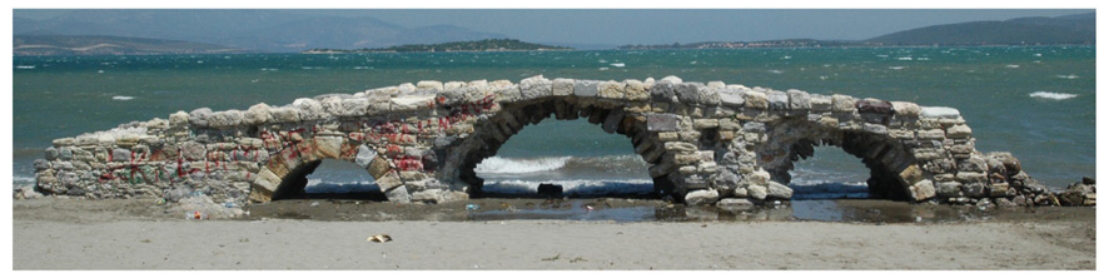

Fig. 1. Southeastern facade of Hypokremnos Viaduct.

techniques to improve and standardize visual data appending condition reports and further detailed reports regarding conservation of irregular ancient monuments. Advantages and disadvantages of automatic and manual image-based modeling techniques are identified to provide adequate data for different survey levels.

Parameters affecting the quality of architectural surveys such as the type of software (Böhler and Heinz, 1999; El-Hakim et al., 2004; Remondino and El-Hakim, 2006; Guidi et al., 2008; Barazzetti et al., 2010; Annibale, 2011; Rosnell and Honkavaara, 2012; Salonia et al., 2009 , etc.) and the reason for the documentation and the related presentation scale (Arias et al., 2005) are evaluated together. Image based photogrammetric software with manual and automatic workflows is tested in terms of visual and metric evaluation of accuracy and level of detail to identify appropriate techniques for condition and structural surveys. The Hypokremnos Viaduct, a monument that has irregular formed and amorphous surfaces is documented with automatic photogrammetric software (Autodesk 123D and Photosynth + Meshlab) and manual photogrammetric software (Tgi3D). The results are compared.

\section{Characteristics of the ancient monument}

The ancient monument, the Hypokremnos Viaduct (Uygun, 2013), is part of a series of remains of viaducts crossing the brooks on the Hypokremnos Plateau, İçmeler, Urla, İzmir. The viaduct is a masonry structure with linear form (W: 3.49, L: 16.37, $\mathrm{h}_{\max }$ : $1.93 \mathrm{~m}$ ) (Fig. 1).

An ancient road connecting the cities of Eryhtrai, Clazomenai and Teos passed through Hypokremnos in the Roman period (Bakır and Anlağan, 1980). The viaduct is thought to have been first constructed in the Roman Period and probably reconstructed with spolia after being demolished during the Turkish period, which started in the region in the 11th century.

The structural integrity of the monument is under risk as a result of the continuous action of waves, salt and sand. Urgent and immediate measures are necessary to prevent further damage. This should be followed by further detailed surveys of structural elements and materials.

\section{Experimentation process}

The experimentation process was composed of two steps, data gathering and data processing in both manual and automatic workflows.

\subsection{Data gathering}

For data gathering, a Nikon D70 digital SLR camera equipped with a $28 \mathrm{~mm}$ lens, a ladder and a steel tape $(20 \mathrm{~m})$ were used. Photos describing the object in general and photos parallel to the surfaces of the object, all overlapping each other, were taken for both automatic and manual evaluation.

\subsection{Data processing}

The data processing phase is composed of two steps; point cloud generation and modeling.

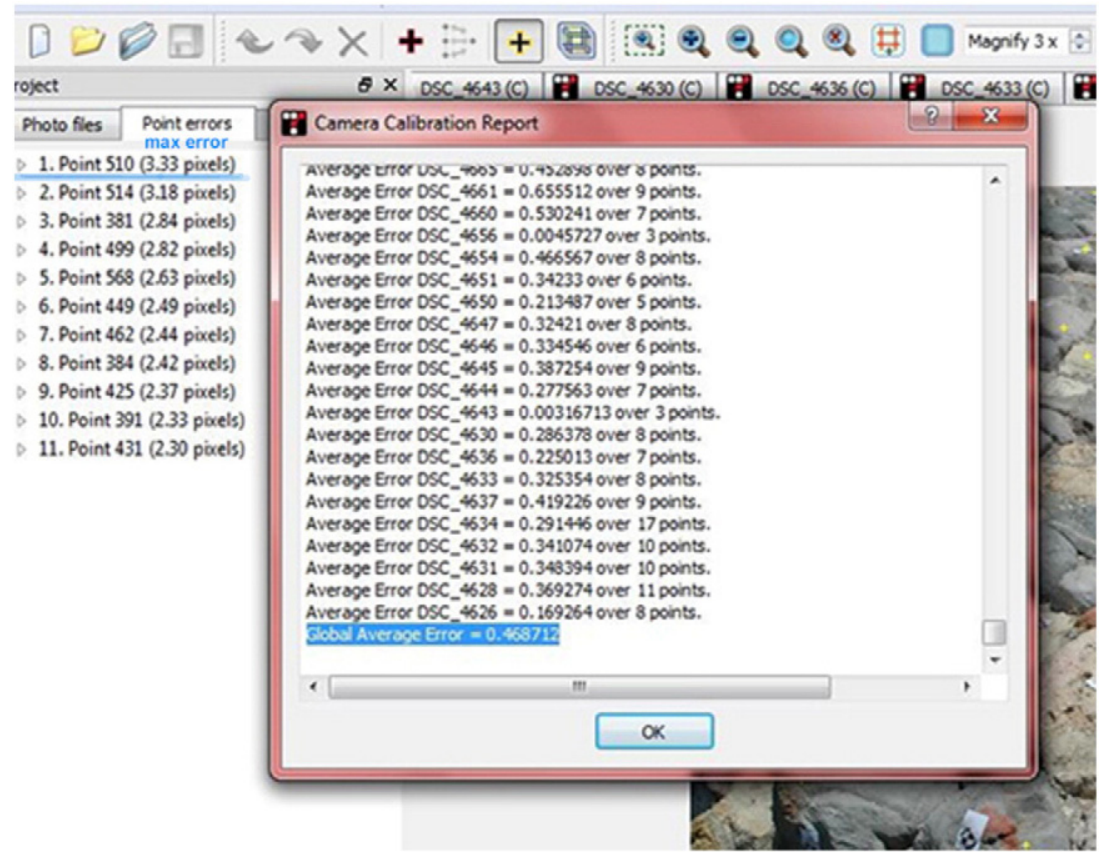

Fig. 2. Global and maximum error values. 
Table 1

Error-scale relationship.

\begin{tabular}{ll}
\hline $\begin{array}{l}\text { Maximum tolerances for scales } \\
\text { (Andrews et al., 2015 and RICS, 2014) }\end{array}$ \\
\hline Scale & Tolerances \\
\hline $1: 5$ & $\pm 4 \mathrm{~mm}$ \\
$1: 10$ & $\pm 5 \mathrm{~mm}$ \\
$1: 20$ & $\pm 6 \mathrm{~mm}$ \\
$1: 50$ & $\pm 15 \mathrm{~mm}$ \\
$1: 100$ & $\pm 30 \mathrm{~mm}$ \\
$1: 200$ & $\pm 60 \mathrm{~mm}$ \\
$1: 500$ & $\pm 150 \mathrm{~mm}$ \\
\hline
\end{tabular}

Table 2

Average error computed between meshes.

\begin{tabular}{ll}
\hline Haussdorf distance calculation & Average error \\
\hline Photosynth on Tgi3D & $5.3 \mathrm{~cm}$ \\
Autodesk 123D on Tgi3D & $14.3 \mathrm{~cm}$ \\
\hline
\end{tabular}

\subsubsection{Point cloud generation}

Calibration and orientation of images were carried out automatically by the automatic software. Images were uploaded to this software and no more interaction was required. In Photosynth, point clouds are automatically placed at the disposal of the web community. Autodesk 123D is fully automatic open source software containing both orientation and modeling tools. In addition, it has manual orientation facilities for photos that cannot be oriented automatically. The model produced can be viewed in wireframe and texture and texture only formats.

Tgi3d allows the orientation of images without any preliminary information about the sensors and does not require calibration. Orientation of image pairs was carried out manually. Image sets were loaded to the software individually and each image pair was oriented, respectively. Three control points were usually sufficient, while for long facades, four or five control points were used to strengthen the bonding system for the corners and damaged short facades. With the automatic addition of control points by the software, the number of control points reached six for the long facades and eight for the short facades.
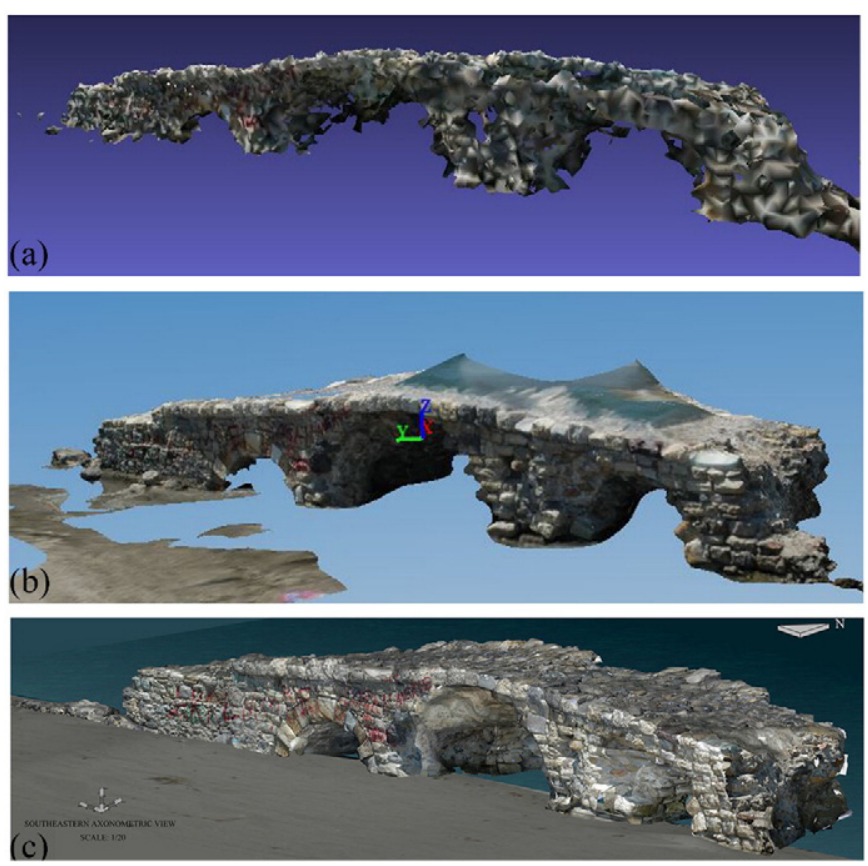

Fig. 4. Textured models of Hypokremnos Viaduct with a) Autodesk 123D b) Tgi3D.

\subsubsection{Reality-based modeling}

In Autodesk 123D, which is fully automatic software, surface construction was carried out automatically. Photosynth does not provide reconstruction of surfaces. Surface construction of point clouds was carried out in Meshlab. The ball pivoting surface reconstruction filter was preferred for the meshing process due to the irregular surfaces of the monuments.

After exporting the point cloud from Tgi3D to SketchUp 8, both the toolbars of SketchUp 8 and the toolbar added to SketchUp 8 automatically by Tgi3D were used for modeling.

A 3D surface was drawn by connecting three control points on the images that were not tilted. This surface was converted to real surface with the Image-Based Surface Modeler toolbar.
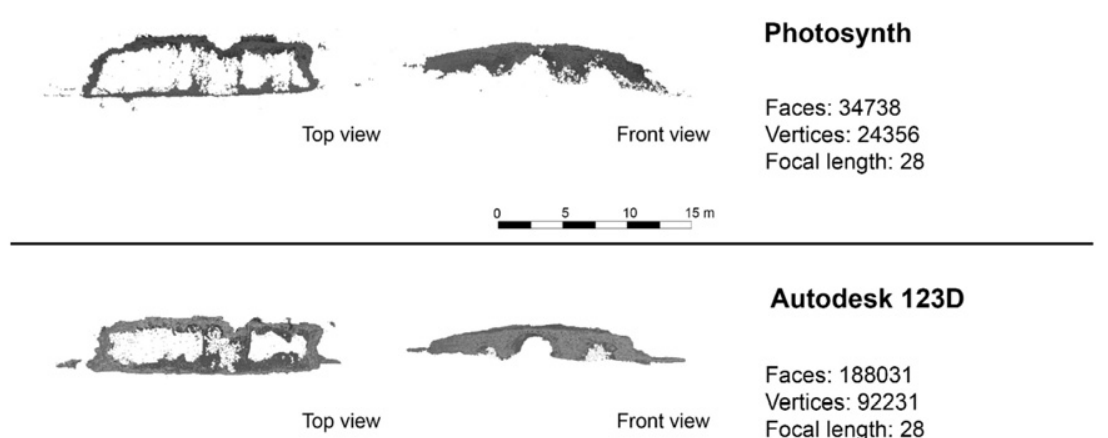

\section{Autodesk 123D}

Faces: 188031

Vertices: 92231

Focal length: 28

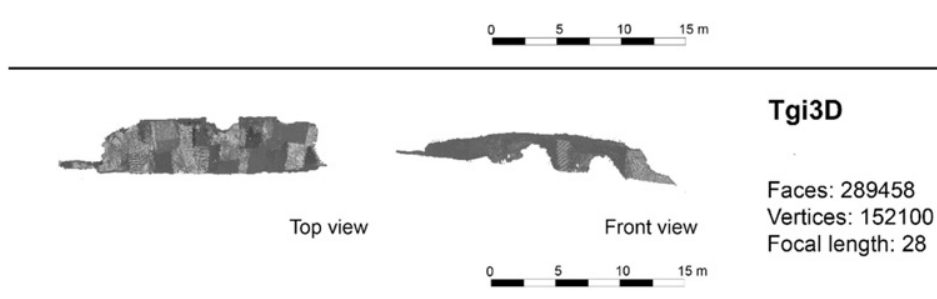

Fig. 3. Visual evaluation of point clouds in $1 / 500$ scale. 


\section{Discussion}

The 3D models are evaluated in terms of precision, level of detail and process time to identify advantages and disadvantages of the selected image-based techniques.

\subsection{Precision}

The precision of the 3D model produced with Tgi3D is calculated considering maximum error value calculated by the software automatically (Fig. 2), the shot length of the object at the site and in the image.

The maximum error amount for $1 / 5$ scale is around $4 \mathrm{~mm}$, therefore, the end product model's precision is more than enough for the acceptable limits of $1 / 5$ scale (Table 1 ).

Also, to test the error values given by the software, dimensions between the targets in the 3D model are checked with traditional measurements.

Maximum error: 3.33 pixels.

Error $(\max ) \sim \mathrm{L} / \mathrm{N} \times$ pixel error $(\max )$.

Error $(\max ) \sim 3450 / 3000 \times 3.33-3.8 \mathrm{~mm}$.
Since the results of Tgi3D have high precision, the models obtained by automatic packages are compared with this model using Haussdorff distance in Meshlab. Hausdorff distance is the maximum distance of a set to the nearest point in the other set (Rote, 1991). First, the problematic vertices created by tilted photos in automatic point clouds were cleaned. Mean distance error values of the vertices gained by automatic techniques were computed using the Tgi3D model as the target mesh. The results demonstrate that the Photosynth package produces more precise 3D models in comparison to Autodesk (Table 2). Nevertheless, the Photosynth model is acceptable for $1 / 200$ scale, while the Autodesk model is for $1 / 500$ scale (Table 2 , Table 1 ).

\subsection{Level of detail}

The images of the roadway were not oriented by automatic techniques since automatic software discarded the images. Thus, point clouds obtained by Autodesk and Photosynth have incomplete parts. However, Autodesk results are more satisfactory than Photosynth. The point clouds of Tgi3D do not have incomplete parts in comparison to automatic evaluations due to the advantages of a human operator.

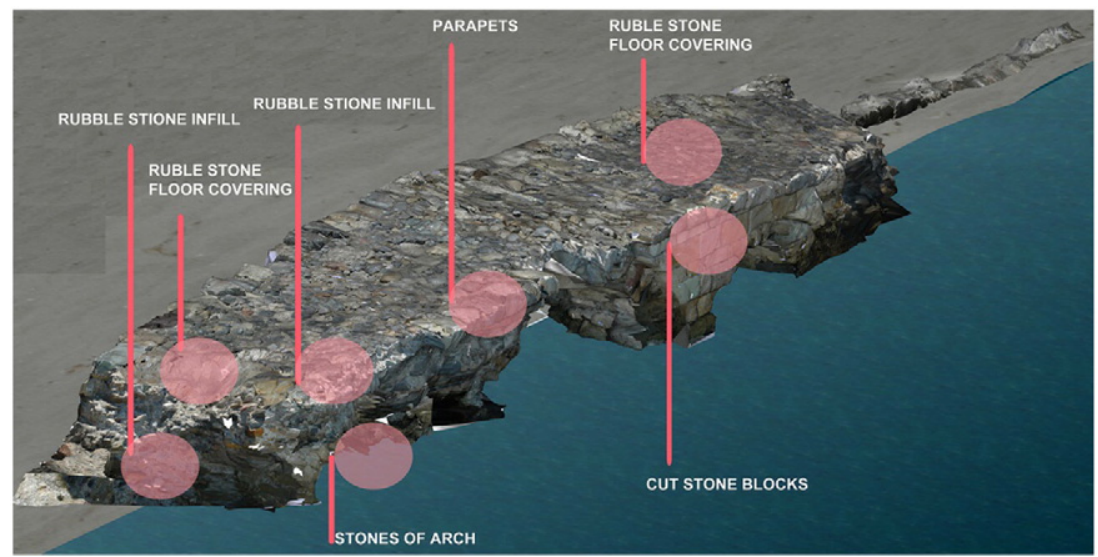

(a)

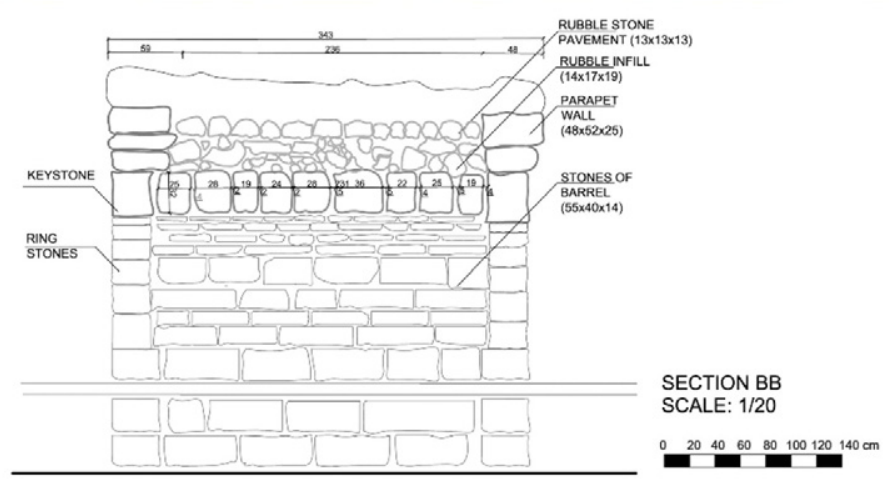

(b)

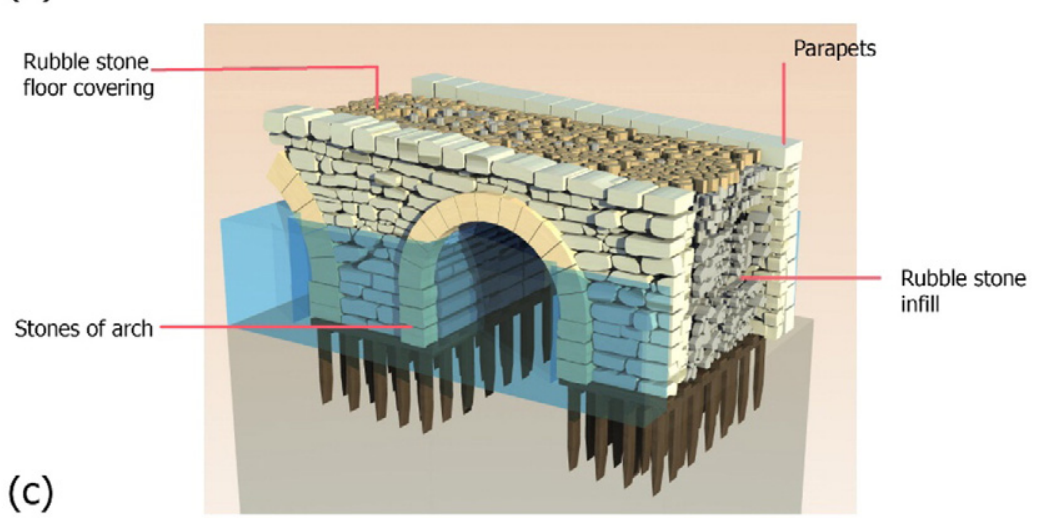

Fig. 5. a. Positions providing structural information, b. System detail, c. Virtual reality model. 


\begin{tabular}{|c|c|c|c|}
\hline 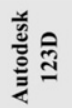 & \multicolumn{2}{|l|}{ Orientation+ Modeling Period } & 30 minutes +15 min (manual stitching time) \\
\hline \multirow{2}{*}{ 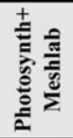 } & \multicolumn{2}{|l|}{ Orientation Period } & 20 minutes \\
\hline & \multicolumn{2}{|l|}{ Modeling Period } & 20 minutes \\
\hline \multirow{2}{*}{ ल) } & Orientation Period & \multicolumn{2}{|c|}{420 hours } \\
\hline & Modeling Period & \multicolumn{2}{|c|}{600 hours } \\
\hline & \multicolumn{2}{|r|}{ Photo number } & Orientation Period \\
\hline & \multicolumn{2}{|r|}{ 10. photo } & 2 seconds \\
\hline & & 15. photo & 4 seconds \\
\hline & & 40. photo & 24 seconds \\
\hline & & 65. photo & 1 minutes 4 seconds \\
\hline & & 100. photo & 7 minutes 30 seconds \\
\hline & & 140.photo & 45 minutes 20 seconds \\
\hline & & 180. photo & 1 hour 30 minutes \\
\hline & & 210. photo & 1 hour 34 minutes \\
\hline
\end{tabular}

Fig. 6. Duration of orientation and modeling.

Discarded images of the roadway also affected the integrity of the mesh and texture in automatic software. Since the points are tied automatically by the automatic software, meshes and surfaces that do not illustrate components of monuments in detail are created automatically for missing parts (Fig. 3). Thus, the level of detail of 3D models produced with automatic techniques is lower than the Tgi3D model (Fig. 4). Comparison of numbers of vertices and faces of the models also supported visual evaluation of the level of detail quantitatively. The Tgi3D model has many more vertices and faces in comparison to automatic models. The number of faces and vertices of the Autodesk 123D have more than the Photosynth model (Fig. 3, Fig. 4).

The Tgi3D model has a high level of detail to provide data about relationships between structural components (Fig. 4.c). The system detail was drawn by collecting data of structural components from different parts of the bridge. This system detail was used to develop the virtual reality model regarded as important for structural intervention decisions.

The mixed structural system detail to be used in intervention decisions of the monument is produced in Autocad 2013 with the help of the reality based 3D model of Hypokremnos Viaduct produced with manual photogrammetric evaluation. In the development of this mixed system detail, not just a specific part of the viaduct is studied but data are collected from different parts of the object that have some deformations (Fig. 5). Construction phases of the historical structure have been interpreted and presented in the virtual reality 3D model with reference to the mixed detail drawing based on the reality based 3D model via Archicad 13.

\subsection{Process time}

The major advantage of automatic techniques is the reduction they provide in the data gathering and processing periods. Taking photos parallel to the surface and illustrating object-surrounding relationship

Table 3

Pros and cons of Autodesk 123D, Tgi3D and Photosynth + Meshlab for surveys.

\begin{tabular}{llll}
\hline & Autodesk & & Photosynth + \\
& 123D & Tgi3D & Meshlab \\
\hline Process time & +++ & + & +++ \\
Reliability & + & +++ & ++ \\
Level of detail & + & +++ & - \\
Necessity of experienced & ++ & +++ & ++ \\
$\quad$ operator & & & \\
\hline
\end{tabular}

is the only requirement. In the office, calibration, orientation and surface construction phases were carried out by the software automatically. However, the detailed Tgi3D model takes a relatively long time (with Intel (R) Core (TM) 2 Duo CPU E8400 @ 3000 GHZ) (Fig. 6).

Processing periods of the automatic software are reasonable for a condition survey if the operator is experienced. Manual software is appropriate for further studies and measures.

\section{Conclusion}

In this study, our experience of some of the capabilities of the photogrammetric evaluation software Photosynth-Meshlab, Autodesk 123D and Tgi3D; was presented and their suitability for various documentation purposes of irregular ancient monuments was discussed (Table 3). Photosynth and Autodesk are user-friendly software programs that provide acceptable scaled presentations of mass characteristics so they are appropriate for supporting condition surveys. They can be useful for inventory, making preliminary evaluations and guiding limited emergency interventions. The manual orientation package, Tgi3D, provides a detailed 3D model illustrating the relationship between all components and materials and can be used for investigation of the structural behavior of the monument and guide the related intervention decisions.

\section{References}

Andrews, D., Bedford, J., Bryan, P., 2015. Metric Survey Specifications for Cultural Heritage. Historic England, Swindon.

Annibale, E., 2011. Image based modeling from spherical photogrammetry and structure for motion. The case of the treasury, Nabatean architecture in Petra. Proceedings of the 23rd International Symposium of the International Scientific Committee for Documentation of Cultural Heritage CIPA 2011 Prague, Czech Republic. http://cipa. icomos.org/fileadmin/template/doc/PRAGUE/038.pdf (accessed 23.05.16).

Arias, P., Herra'ez, J., Lorenzo, H., Ordonez, H., 2005. Control of structural problems in cultural heritage monuments using close-range photogrammetry and computer methods. Comput. Struct. 83 (21-22), 1754-1766.

Bakır, G., Anlağan, G., 1980. 1979 Yılı Klazomeani Kazısı. II. Kazı Sonuçları Toplantısı, p. 90.

Barazzetti, L., Scaioni, M., Remondino, F., 2010. Orientation and 3d modelling from markerless terrestrial images: combining accuracy with automation. Photogramm. Rec. 25 (132), 356-381.

Böhler, W., Heinz, G., 1999. Documentation, surveying, photogrammetry. Proceedings of XVII CIPA Symposium. Recife, Olinda, Brazil (http://www.i3mainz.fh-mainz.de/ publicat/cipa99/cipa99.pdf (accessed 23.05.16)).

El-Hakim, S.F., Beraldin, J.A., Picard, M., Godin, G., 2004. Detailed 3D reconstruction of large-scale heritage sites with integrated techniques. IEEE Comput. Graph. Appl. 24 (3), 21-29.

Guidi, G., Remondino, F., Russo, M., Rizzi, A., Voltolini, F., Menna, F., Fassi, F., Ercoli, S., Masci, M.E., Benedetti, B., 2008. A multi-resolution methodology for archeological survey: the Pompeii forum. In: Ioannides, M., Addison, A., Georgopoulos, A., 
Kalisperis, L. (Eds.), Proceedings of 14th International Conference on Virtual Systems and Multimedia, Limassol, Cyprus. Archaeolingua, Budapest.

RICS, 2014. Measured Surveys of Land, Buildings and Utilities RICS Guidance Note. third ed. (London: UK).

Remondino, F., El-Hakim, S., 2006. Image -based 3D modeling: a review. Photogramm. Rec. 21 (115), 269-291.

Rosnell, T., Honkavaara, E., 2012. Point cloud generation from aerial image data acquired by a quadrocopter type micro unmanned aerial vehicle and a digital still camera. Sensors $12(1), 453-480$.
Rote, G., 1991. Computing the minimum Hausdorff distance between two point sets on a line under translation. Inf. Process. Lett. 38, 123-127.

Salonia, P., Scolastico, S., Pozzi, A., Marcolongo, A., Messina, T.L., 2009. Multi-scale cultural heritage survey: quick digital photogrammetric systems. J. Cult. Herit. 10 (1), 59-64.

UNI EN 16096, 2012. Conservation of Cultural Property-Condition Survey and Report of Built Cultural Heritage. European Committee for Standardization.

Uygun, F., 2013. Photogrammetric Evaluation Options for Ancient Structures in Hypokremnos, Pagos, Paradiso and Nysa. Master Thesis. IZTECH, İzmir: Turkey. 